\title{
Psychological and Behavioral Factors Associated with Cyclic Vomiting Syndrome: Case Report
}

\author{
I. Putu Candra S. Sutarta ${ }^{1 *}$, I. Gusti Ayu I. Ardani ${ }^{1}$, Luh Nyoman A. Aryani ${ }^{1}$, I. Gusti Ayu T. Windiani ${ }^{2}$, \\ I. Gusti Ngurah S. Adnyana ${ }^{2}$, Yunias Setiawati ${ }^{3}$
}

${ }^{1}$ Department of Psychiatry, Medical Faculty, Udayana University, Sanglah General Hospital, Denpasar, Bali, Indonesia; ${ }^{2}$ Department of Paediatrics, Medical Faculty, Udayana University, Sanglah General Hospital, Denpasar, Bali, Indonesia; ${ }^{3}$ Department of Psychiatry, Medical Faculty, Airlangga University, Dokter Soetomo Hospital, Surabaya, East Java, Indonesia

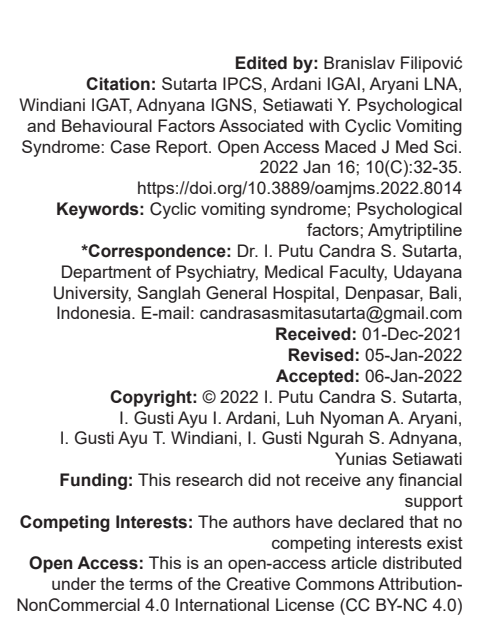

\begin{abstract}
BACKGROUND: Cyclic vomiting syndrome (CVS) is a disorder of unknown etiology and pathogenesis characterized by recurrent and stereotypical vomiting episodes with varying intervals from baseline or normal health in between. The biopsychosocial model proposes that disease does not result from a single etiology but from systems that interact simultaneously at the cellular, tissue, organismal, interpersonal, and environmental levels. In addition, psychosocial factors have direct and reverse physiological and pathological consequences.

CASE REPORT: In this case report, a 17-year-old boy was consulted to the psychiatry department because of repeated vomiting suspected of psychological factors. The patient was hospitalized due to vomiting. This vomiting has been experienced by the patient since around 2 months before the examination. Patient's father and stepmother actually really love this patient, but in the patient's perception, the patient's father and mother are less adequate in how to show their affection. The patient realized that his father loved him but felt in some ways, the patient was uncomfortable because he felt that he did not fit his father's mindset.

CONCLUSION: The patient was diagnosed with Psychological and Behavioral Factors Associated with CVS (F54). Pharmacological therapy with $12.5 \mathrm{mg}$ Amytriptiline tablet, $0.5 \mathrm{mg}$ Risperidone tablet, and $5 \mathrm{mg}$ Clobazam tablet every $24 \mathrm{~h}$ orally (evening), while the non-pharmacological therapy given was supportive psychotherapy and psychoeducation to the parent.
\end{abstract}

\section{Introduction}

Intestinal disorders are thing that everyone has experienced in their life. Following the progress of science and knowledge, scientists found association between mental problems and disorders that appears in intestine. Associated with those findings, recent discoveries found an interesting fact that children and adolescents commonly experiencing vomits which organic causes are not significant or often the vomiting symptom appeared with mental problems [1].

While the traditional dualistic model of human health separates the activities of the mind from the body, there is recently an understanding of the close association between these two entities. Instead of dualism, human disease is best understood through a biopsychosocial model, which assesses the interplay and significance of biological, environmental, and psychological factors. Gastrointestinal disease provides useful applications for biopsychosocial models, particularly as our knowledge of the brain-gut-microbiome axis continues to evolve.
This bidirectional communication system between the central nervous system and the enteric nervous system is influenced by the gut microbiome and is dependent on immune, endocrine, nervous, and metabolic pathways. The brain-gut-microbiome axis maintains intestinal homeostasis, and its dysregulation has been implicated in various gastrointestinal diseases, especially disorders of gut-brain interactions. This circular circle of communication linking mind and body provides a physiological rationale for the interpretation of gastrointestinal disease in a biopsychosocial model [1], [2], [3], [4].

Somatoform disorders differ from other psychiatric disorders in two main respects: First by the fact that the complaints are physical and not psychological; second because parents and children usually attribute these symptoms to physical illness even though there is no medical evidence, including a physical examination and investigation. Consequently somatoform disorders tend to present to a psychiatrist only after repeated pediatric or other specialist examinations have been performed, and referrals 
may be received only with reluctance by a number of families who are sceptical about the usefulness of psychiatric assessments, even sometimes hostile to this [5], [6], [7].

Cyclic vomiting syndrome (CVS) is a disorder of unknown etiology and pathogenesis characterized by recurrent and stereotypical vomiting episodes with varying intervals from baseline or normal health in between. Recent articles and proceedings from two international conferences on CVS published in the past decade have defined this disorder in detail and its proposed mechanisms and potential treatments. These publications and symposia have provided important steps in recognizing and understanding an underrecognized and often misdiagnosed disorder. Typical misdiagnoses include gastroenteritis, gastroesophageal reflux, food poisoning, recurring "flu," and eating disorders. Although CVS can begin in infancy, the median age of onset in this group is 4.8 years. As a measure of misdiagnosis, the median interval from symptom onset to proper recognition was 1.9 years, during which time the child had suffered approximately 15 episodes or more. Although the prevalence and incidence of CVS are unknown, current estimates in school-based surveys of Caucasian children aged 5-15 years report a prevalence of $2 \%$. Although CVS is clearly often misdiagnosed, in our experience this figure appears to be excessive, perhaps because the study was based on a questionnaire that did not involve exclusive testing and because milder cases that did not require medical intervention were detected. However, in our reported pediatric gastroenterology experience, CVS is second only to gastroesophageal reflux disease as a cause of recurrent vomiting. Similar to the gender profile in migraine headaches, there is a slight female predominance over males (57\%:43\%). This case is common we found in practice, but sometimes we forgot to explore the psychological aspects of patients with physical illnesses [8], [9], [10], [11].

\section{Case Report}

A 17-year-old boy was consulted to the psychiatry department because of repeated vomiting suspected of psychological factors. He was interviewed in the pediatric ward in a sitting position on a chair next to the bed facing the examiner. During the interview, patient was sitting calmly. Then during the examination, patient vomited several times which was collected by him in a jar.

The patient said he was hospitalized due to vomiting. This vomiting has been experienced by the patient since around February 2021 (2 months before the examination). The patient said he did not know the cause of his vomiting. Vomiting is felt quite often, almost every 15 min the patient vomits. For the past few days, patient has been vomiting with vomit mostly liquid. Due to the vomiting, patient had lost $10 \mathrm{~kg}$ of weight within 2 months.

Prior to experiencing this vomiting, the patient often felt his stomach was bloated and sometimes because his stomach was bloated the patient experiencing dyspnea. This symptom had been felt since July 2020, at that time the patient did feel pressured in his life. The patient said that at that time he and his father often had disagreements where the patient felt that his biological father always opposed his every wish. Even so, the patient felt that since January the condition of disagreement with his father had compromised, but in February the patient started vomiting.

The patient is the first child of 3 siblings where the patient has 1 younger brother and 1 step brother. The patient's younger brother is currently 13 years old, a boy. He is close enough to the patient although he and patient has some minor argues most of the times which are normal for siblings. Patient's step brother is currently 4 years old and patient loves his step brother like his own brother. The patient's father remarried around 2015 after the patient's biological mother passed away in the same year. The patient had no significant problem with his stepmother; felt that his stepmother was kind and caring like his own biological mother and not seeing differently between her biological children and her stepsons.

However, several occasions the patient experienced disagreements with his father where the patient often being disagreed and felt that his father had underestimated his illness. Likewise with the stepmother, sometimes the patient expects his stepmother to act like his biological mother who can listen to the patient's complaints when the patient vents and gives massages to the patient when the patient feels uncomfortable.

Based on the heteroanamnesis, patient's stepmother said that he (patient) started vomiting since February 2021. The patient's parents did not know what caused the vomits. However, the patient began to look sick since around July 2020 where the patient began to look often nauseous and seemed short of breath. The patient's stepmother said that her son did not talk much about his illness and also according to his stepmother the patient was a quiet person and mostly kept his problems to himself. Patient's stepmother also mentioned that he has strong wills, before this illness patient had never shown any symptoms that he is going through a lot of pressure. But at some point of time, he had shown himself a little depressed.

According to his father, the patient was a little less willing to talk to him because according to his father, maybe he was a little harsh but his father was strict for the good of his son. In addition, the patient's father 
also felt that he was still carried away by the upbringing of the patient's grandfather who was harsh and rude to him. But after patient was sick, his father promised to be more patient and not harsh on him anymore. In addition, the patient's father also has a tendency to be anxious and think about things excessively, but over time his father has begun to be able to organize his thoughts.

Due to physical examination, there was no significant finding. Laboratory examinations which include routine blood test, Aspartate aminotransferase, alanine aminotransferase, bilirubin, albumin, globulin, and gamma glutamyl transpeptidase showed that there was no significant finding. Fecal routine and fecal occult blood test also showed no significant finding. Due to esophago-gastric-duodenoscopy, the finding was erosive esophagitis, antral superficials gastritis. We used two psychometric tools, Child Depression Inventory which gave us score of 28 that interpreted as the patient was suspected to be depressed and Beck's Depression Inventory which gave us score of 18 that interpreted as borderline of clinical depression.

The diagnosis of this patient according to the International Statistical Classification of Diseases and Related Health Problems 10 (ICD-10) in Axis I was Psychological and Behavioural Factors Associated with CVS (F54), in Axis II was anankastic personality trait with defense mechanism repression, in Axis III was CVS and syndrome dyspepsia, in Axis IV was problem with primary support group, and in Axis $\checkmark$ was GAF score during examination 60-51. The patient was given pharmacology therapy with $12.5 \mathrm{mg}$ Amytriptiline tablet, $0.5 \mathrm{mg}$ Risperidone tablet, and $5 \mathrm{mg}$ Clobazam tablet every $24 \mathrm{~h}$ orally (evening), while the non-pharmacological therapy given was supportive psychotherapy and psychoeducation to the parent.

After 10 days of psychiatric treatment (in total of 29 days of hospitalization), this patient showed up improvement. He vomited less, in average 10 times a day which prior almost every $15 \mathrm{~min}$ he vomited. He also could control his emotion more and less arguing with his father. The relations between him and his father were getting better and they could communicate more effective.

\section{Discussion}

The patient is a 17-year-old male adolescent, Muslim, Javanese, currently just graduated from Vocational High School and has not continued to college, not married, currently not working. The patient was consulted to the psychiatry department because of repeated vomiting with suspicion of psychological factors.
This case was diagnosed as Psychological and Behavioural Factors Associated with CVS (F54) according to the ICD-10 and DSM 5 with the differential diagnosis was moderate episode of depression with somatic symptoms [12], [13]. There were no biological factors found in this patient. From the psychological factor, the father and stepmother actually really love the patient, but in the patient's perception, his father and stepmother are less adequate in the way they showing their affection this was what we suspected as the main problem that patient was struggling with. The patient realized that his father loved him but felt in some ways, the patient was uncomfortable because he felt that he did not fit his father's mindset. From the socio-economic factors of patients from sufficient families so that they are able to provide treatment [14], [15].

In a study that aiming to compare the effectiveness in CVS prophylaxis, it was found that amitriptyline and cyproheptadine are both effective in CVS prophylaxis and neither has an advantage over the other. Based on another research, 21 of 32 patients $(65.6 \%)$ in the amitriptyline group and 16 of 32 patients $(50 \%)$ in the cyproheptadine group reported no further attacks. They also found that four patients $(18 \%)$ in the amitriptyline group and one patient $(17 \%)$ in the cyproheptadine group showed a partial response to treatment, defined as a $50 \%$ reduction in attack frequency, whereas due to another research showed that eight patients $(25 \%)$ in each group experienced partial remission. The differences mentioned were not statistically significant, which led us to conclude that amitriptyline and cyproheptadine are equally effective for the prophylaxis of CVS [16].

\section{Conclusion}

This case reminds us that many cases with appearance of somatic symptoms are caused by mental conditions. This case showed improvement after the collaboration treatments through the physical and psychological.

\section{Acknowledgments}

We would like to thank all that participated in this case report. More specifically, we would like to acknowledge Department of Psychiatry and Department of Paediatric of Sanglah Hospital to provide and permit us to do this case report. 


\section{References}

1. Person $\mathrm{H}$, Keefer L. Psychological comorbidity in gastrointestinal disease: Update on the brain-gut-microbiome axis. Prog Neuropsychopharmacol Biol Psychiatry. 2020;107(20):110209. https://doi.org/10.1016/j.pnpbp.2020.110209

PMid:33326819

2. Mader SS. Understanding Human Anatomy and Physiology. New York: The McGrew-Hill; 2006.

3. Sleisenger MH, Feldman M, Friedman LS, Brandt LJ. Sleisenger and Fordtran's Gastrointestinal and Liver Disease: Pathophysiology, Diagnosis, Management. Philadelpia, PA: Saunders/Elsevier; 2010.

4. Leigh H, Streltzer J. Handbook of Consultation-Liaison Psychiatry. New York: Springer; 2008.

5. Garralda ME. Functional somatic symptoms and somatoform disorders in children. In: A Clinician's Handbook of Child and Adolescent Psychiatry. Cambridge: Cambridge University Press; 2005. p. 246-70.

6. World Health Organization. Available from: http://www.who.int/ tropics/depression/en. [Last accessed on 2017 Mar 6].

7. Boland R, Verduin ML, Ruiz P. Kaplan and Saddock's Synopsis of Psychiatry. $12^{\text {th }}$ ed. Philadelphia, PA: Wolters Kluwer; 2022.

8. Sunku B, Li BU. Cyclic vomiting syndrome. In: Textbook of Gastroenterology and Nutrition. London: Taylor and Francis Group; 2004. p. 289-302.

9. Amos JJ, Robinson RG. Psychosomatic Medicine an Introduction to Consultation-Liaison Psychiatry. Cambridge:
Cambridge University Press; 2010.

10. Yao X, Yang Y, Zhang S, Shi Y, Zhang Q, Wang Y. The impact of overlapping functional dyspepsia, belching disorders nad functional heratburn anxiety, depression and quality of life of chinese patients with irritable bowel syndrome. BMC Gastroenterol. 2020;20:209.

11. Rathi P, Gill A, Vankar GK, Ohri N, Patel A. Study of depression and anxiety in endoscopically diagnosed cases of gastrooesophageal reflux disease (GERD). Indian J Ment Health. 2018;5(3):307-16.

12. Departemen Kesehatan R.I. Direktorat Jenderal Pelayanan Medik, Pedoman Penggolongan Diagnosis Gangguan Jiwa di Indonesia III, Jakarta: Departemen Kesehatan RI; 1993.

13. American Psychiatric Association. Diagnosis and Statistical Manual for Mental Disorders. Arlington: American Psychiatric Association, 2013.

14. Kim SY, Kim HJ, Lim H, Kong IG, Kim M, Choi HG. Bidirectional Association Between Gastrophageal Reflux Disease and Depression: Two Different Nested Case-control Studies Using A National Sample Cohort, Scientific Reports; 2018. p. 1-8.

15. Wise MG, Rundell JR. Clinical Manual of Psychosomatic Medicine A Guide to Consultation-Liaison Psychiatry. Arlington: American Psychiatric Publishing, Inc.; 2005.

16. Badihian N, Saneian H, Badihian S, Yaghini O. Prophylactic therapy of cyclic vomiting syndrome in children: Comparison of amitriptyline and cyproheptadine: A randomized clinical trial. Am J Gastroenterol. 2018;113(1):135-40. https://doi.org/10.1038/ ajg.2017.194

PMid:28719594 